\title{
Plant originated glycoprotein has anti-oxidative and anti-inflammatory effects on dextran sulfate sodium-induced colitis in mouse
}

\author{
Phil-Sun Oh \& Kye-Taek Lim* \\ \#521, Molecular Biochemistry Laboratory, Institute of Biotechnology, Chonnam National University, \\ 300 Yongbong-Dong, Kwangju, 500-757, South Korea
}

Received 6 December 2005; accepted 5 March 2006

(c) 2006 National Science Council, Taipei

Key words: myeloperoxidase activity, reactive oxygen species, NF-кB (p50), GJE glycoprotein

\begin{abstract}
Summary
We investigated the preventive effect of glycoprotein $(27 \mathrm{kDa})$ isolated from Gardenia jasminoides Ellis (GJE) fruits on colitis in dextran sulfate sodium (DSS, 3\%)-induced A/J mice which were administrated orally for 7 days. Anti-inflammatory activity of GJE glycoprotein was assessed by neutrophil infiltration and colonic lipid peroxidation, and determined by myeloperoxidase (MPO) activity and levels of thiobarbituric acid reactive substances (TBARS), respectively in DSS treatment system. The activities of antioxidative enzymes [catalase (CAT), superoxide dismutase (SOD), and glutathione peroxidase (GPx)], activation of inflammation related mediators (iNOS, COX-2, and NF- $\kappa \mathrm{B}$ ), and production of nitric oxide (NO) and reactive oxygen species (ROS) were also measured. The results of this study showed that GJE glycoprotein $(80 \mu \mathrm{g} / \mathrm{ml})$ has a scavenging property to inhibit the intracellular ROS production in RAW 264.7 cells and that GJE glycoprotein $(80 \mathrm{mg} / \mathrm{kg} \mathrm{BW})$ significantly suppressed the increase in the MPO activity, TBARS level, and NO production, inflammation related mediators [iNOS, COX-2, and NF- $\mathrm{KB}$ (p50)] activity in DSS-induced mice. Interestingly, the activities of CAT, SOD, and GPx were gradually augmented after a supplement of GJE glycoprotein. Therefore, we suggest that GJE glycoprotein is preventive and therapeutic agent for the ulcerative colitis.
\end{abstract}

\section{Introduction}

Colon cancer is one of the most frequent causes of cancer-related death in Korea, and it is continuously increase because of the rapid change in dietary life. The initiation of colon cancer is closely associated with serious sequelae of the inflammatory bowel diseases (IBD), but its precise mechanism is unknown and debated [1].

Ulcerative colitis (UC), one of the IBD, is a recurrent inflammatory disease of large intestine, and characterized by bloody diarrhea, intestinal mucosal ulceration, and systemic symptoms [2].

*To whom correspondence should be addressed: Tel: + 82-62530-2115; Fax: +82-62-530-2129; E-mails:ktlim@chonnam. ac.kr; kyetaeklim@hotmail.com
Several evidences suggest that such intestinal condition is mediated by the activated nonlymphoid cells such as macrophages [3]. Once large numbers of neutrophils and macrophages are activated, these cells enter the injured mucosa of large intestine, leading to overproduction of oxygen free radicals and nitric oxide (NO) [4]. An increase of reactive oxidants in inflamed tissue can cause injury to target cells and also damage DNA, which could contribute to gene mutation and cancer development [5]. In addition, there are changes in the enzymatic as well as non-enzymatic antioxidant defense systems such as superoxide dismutase (SOD), catatalase (CAT), glutathione peroxidase (GPx), ascorbic acid, $\alpha$-tocopherol, and glutathione during 
inflammatory processes, suggesting a reduced resistance to reactive oxidants-mediated damage $[6,7]$. These defense systems represent the essential defense against the potential toxicity of reactive oxidants generated by severe oxidative conditions such as chronic inflammation and abnormal metabolism. Therefore, many researchers have tried to obtain bioactive substances which have a cytoprotective ability against cellular oxidative damage, as well as an enhancing ability on antioxidant enzyme activities [8,9]. One of the most ubiquitous transcription factors that regulate gene expressions involved in cellular proliferation, inflammatory responses, and cell adhesion is nuclear factor- $\mathrm{\kappa B}$ (NF- $\mathrm{\kappa B})$. It exists as a heterodimer of p50 and p65 subunits complexed with the inhibitory subunit (I $\kappa B$ ) that prevents migration of $\mathrm{p} 50 / \mathrm{p} 65$ to the nucleus. The activated NF- $\kappa \mathrm{B}$ is then able to translocate into the nucleus, where it binds to specific DNA sequence, thereby controlling their expression [10]. It is well-defined that several binding sites for transcriptional factor (NF- $\kappa B$ ) are located in the enhancer- or basal promoter region of pro-inflammatory genes including COX-2 and iNOS [11, 12]. Hence, the inhibition of such mediators by an agent is closely related to its anti-inflammatory activity.

Traditionally, Gardenia jasminoides Ellis (GJE) has been used as a food additive and a herbal medicine for a long time [13]. Recently, we isolated glycoprotein from GJE fruits (GJE glycoprotein), and found that it has an approximate molecular mass of $27 \mathrm{kDa}$, and consists of carbohydrate contents $(57.65 \%)$ and protein contents $(42.35 \%)$ [14]. In a previous study, our results showed that GJE glycoprotein has strong anti-oxidative abilities and modulatory effects on the cellular biological functions, such as oxidative stress-induced apoptosis via redox-sensitive signal mediators, protein kinase $\mathrm{C}(\mathrm{PKC})$ and nuclear factor- $\mathrm{\kappa} \mathrm{B}$ (NF-KB). However, there is no evidence of its biological effect on experimental inflammatory animal models.

In this study, we investigated MPO activity and levels of TBARS, activities of antioxidative enzymes and inflammation related mediators, and productions of nitric oxide (NO) and reactive oxygen species (ROS) to understand the intestinal anti-inflammatory effects of GJE glycoprotein in DSS-induced A/J mouse.

\section{Materials and methods}

\section{Chemicals}

All the plastic materials were purchased from Falcon Labware (Becton-Dickinson, Franklin Lakes, NJ). Dextran sulfate sodium (molecular weight: $36,000-50,000)$ was purchased from ICN Biomedicals (Meckenheim, Germany). Lipopolysaccaride (LPS, L2637), and 2', 7'-dichlorofluorescein diacetate (D6883) were obtained from Sigma (St Louis, MO, USA). Other chemicals and reagents were of the highest quality available.

\section{Preparation of GJE glycoprotein}

The fruits of Gardenia jasminoides Ellis were collected from Naju traditional market in the Chonnam province of South Korea, and GJE glycoprotein was isolated from it as described previously [14]. The purity of GJE glycoprotein is more than $95 \%$. The dried sample $(30.5 \mathrm{mg}$, $0.61 \%$ from the original sample) was stored at $-20{ }^{\circ} \mathrm{C}$ during the experimental period. We used GJE glycoprotein with a molecular weight of $27 \mathrm{kDa}$ in this study.

\section{Animals and cell culture}

Male mice (A/J), aged 5 weeks, were purchased from Daehan Lab. (Animal Research Center Co., Ltd, Dae Jeon, Korea) and housed according to the animal care guidelines approved by the Animal-care Committee of the American Society of Mammalogists [15] at the Experimental Animal Room of Veterinary College of Chonnam National University (CNU). The mice were fed a commercial diet and water ad libitum during all experimental periods, and kept for at least 1 week prior to the experiments. On the other hands, RAW 264.7 cells (murine macrophage cell line) were incubated in DMEM containing $10 \%$ FBS, $100 \mathrm{U} / \mathrm{ml}$ penicillin, and $100 \mu \mathrm{g} / \mathrm{ml}$ streptomycin at $37{ }^{\circ} \mathrm{C}$, and $5 \% \mathrm{CO}_{2}$ atmosphere. The number of cells $\left(1 \times 10^{6}\right.$ cells $\left./ \mathrm{ml}\right)$ was divided into 96-well flat bottom plates.

\section{Induction of ulcerative colitis (UC)}

Colitis was induced by DSS with some modification from the method of Kitajima et al. [16]. After 
1 week acceleration period, the $\mathrm{A} / \mathrm{J}$ mice were weighed and randomly divided into five groups with eight mice per group (control, GJE glycoprotein treatment alone, $3 \%$ DSS, or GJE glycoprotein treatment groups with $3 \%$ DSS). GJE glycoprotein (40 and $80 \mathrm{mg} / \mathrm{kg}$ ) was administered orally by means of a catheter once a day for 10 days prior to $3 \%$ DSS supplement, and control group was administered with $100 \mu \mathrm{l}$ of phosphate buffered saline (PBS). Mice were induced colitis by replacing normal drinking water with distilled water containing $3 \%$ DSS $(\mathrm{w} / \mathrm{v}$, prepared daily, molecular weight $36,000-50,000$ ) for 7 days. Animals were sacrificed after 17 days from the beginning of the experiment.

Mouse body weight, the presence of gross blood in the feces, and stool consistency were recorded daily throughout the experiments. A score was assigned to each of these parameters according to the criteria proposed by Cooper et al. [17] (Table 1), and used to calculate an average daily disease activity index (DAI) for each animal. Once mice were killed by cervical dislocation, their colons were immediately removed, rinsed with ice-cold PBS and processed for colonic iNOS and COX-2 expression, MPO activity, and the levels of TBARS. The mice blood were collected by a cardiac puncture and then centrifuged at $1,500 \times \mathrm{g}$ for $20 \mathrm{~min}$, and the supernatant was stored at $-70{ }^{\circ} \mathrm{C}$. On the other hand, to determine the toxicity of GJE glycoprotein and DSS, relative values of body weight was calculated as shown in equations.

$$
\begin{aligned}
& \text { Relative value of } \mathrm{BW} \\
& \quad=[\mathrm{BWB}(\mathrm{g})-\mathrm{BWA}(\mathrm{g})] / \mathrm{BWB}(\mathrm{g}) \times 100
\end{aligned}
$$

It means that BW is the body weight, and BWB is the body weights before administration, while BWA is the body weights after administration.

\section{Myeloperoxidase (MPO) activity}

The level of tissue MPO was determined in accordance with a standard enzymatic procedure as described by Krawisz et al. [2], with minor modifications. In brief, the tissue specimen was homogenized in $50 \mathrm{mM}$ potassium phosphate buffer (pH 6.0) with $0.5 \%$ hexadecyltrimethylammonium bromide using a Polytron-type homogenizer three times for $30 \mathrm{~s}$ each on ice. The sample was centrifuged at $20,000 \times \mathrm{g}$ for $10 \mathrm{~min}$ at $4{ }^{\circ} \mathrm{C}$, and the supernatant was collected. This sample $(100 \mu \mathrm{l})$ was added to $2.9 \mathrm{ml}$ of $50 \mathrm{mM}$ phosphate buffer (pH 6.0) containing $0.167 \mathrm{mg} / \mathrm{ml} \mathrm{O}$-dianisidine hydrocholoride and $0.0005 \%$ hydrogen peroxide. The absorbance at $460 \mathrm{~nm}$ in the sample was measured using a spectrometer at $25^{\circ} \mathrm{C}$. The protein concentration of the supernatant was determined using a Lowry method [18], and the values were standardized using MPO purified from human leucocytes (Sigma, St Louis, MO, USA). One unit of change in MPO level was defined as the value that can degrade $1 \mu \mathrm{M} \mathrm{H}_{2} \mathrm{O}_{2}$ per minute at $25^{\circ} \mathrm{C}$. And, the values were calculated as a percentage of the control value.

\section{Measurement of ROS}

Amount of ROS was measured by using nonfluorescent $2^{\prime}, 7^{\prime}$-dichlorodihydrofluorescein $\left(\mathrm{H}_{2} \mathrm{DCF}\right.$ DA). $\mathrm{H}_{2}$ DCF-DA is a fluorogenic freely permeable tracer specific for ROS assessment. It is deacetylated by intracellular esterases to the non-fluorescent $2^{\prime}, 7^{\prime}$-dichlorohydrofluorescein (DCFH), which is oxidized to the fluorescent compound $2^{\prime}, 7^{\prime}$-dichlorofluorescein (DCF) by ROS. Cells were pre-incubated with $10 \mu \mathrm{M} \mathrm{H}_{2}$ DCF-DA for

Table 1. Scoring of disease activity index (DAI).

\begin{tabular}{llll}
\hline Score & Weight loss $(\%)$ & Stool consistency* & Occult/gross bleeding \\
\hline 0 & None & Normal & Negative \\
1 & $1-5$ & Loose stools & Negative \\
2 & $5-10$ & Loose stools & Hemoccult positive \\
3 & $10-20$ & Diarrhea & Hemoccult positive \\
4 & $>20$ & Diarrhea & Gross bleeding \\
\hline
\end{tabular}

*Normal stools = well formed pellets; loose stools = pasty and semi-formed stools which do not stick to the anus; diarrhea $=$ liquid stools that stick to the anus.

The DAI value is the combined the scores of weight loss, stool consistency, and bleeding divided by 3 [17]. 
30 min at $37^{\circ} \mathrm{C}$, and then washed twice with PBS to remove the excess of $\mathrm{H}_{2}$ DCF-DA. After that, the cells were co-treated with GJE glycoprotein (40 and $80 \mu \mathrm{g} / \mathrm{ml})$ in presence of LPS $(200 \mathrm{ng} / \mathrm{ml})$. Finally, the fluorescence intensity was measured at excitation wavelength of $485 \mathrm{~nm}$ and emission wavelength of $530 \mathrm{~nm}$ using fluoresencent microplate reader (Dual Scanning SPECTRAmax, Molecular Devices Corporation, Sunnyvale, CA, USA). The values were calculated as relative intensity of DCF fluorescence, compared with the control.

\section{Plasma NO levels}

The NO production was assessed indirectly by measuring the nitrite levels in plasma determined by a calorimetric method based on the Griess reaction [19]. Plasma samples were diluted four times with distilled water and deproteinized by adding $1 / 20$ volume of zinc sulfate $(0.3 \mathrm{~g} / \mathrm{ml})$ to a final concentration of $0.015 \mathrm{~g} / \mathrm{ml}$. After centrifugation at $10,000 \times \mathrm{g}$ for $5 \mathrm{~min}$, the supernatant $(100 \mu \mathrm{l})$ was mixed with $100 \mu \mathrm{l}$ of Griess reagent ( $1 \%$ sulfanilamide and $0.1 \% N$-1-naphthylethylenediamine dihydrochloride in $2.5 \%$ polyphosphoric acid). After $10 \mathrm{~min}$ at room temperature, the absorbance was measured at $540 \mathrm{~nm}$ with a MicroReader (Hyperion, Inc., USA). Nitrite was quantified by using sodium nitrate as a standard curve.

\section{TBARS assay}

Lipid peroxidation was estimated according to the presence of TBARS in colonic tissue using the method of Ohkawa et al. [20]. Briefly, the animals were killed under deep ether anesthesia and the large intestine removed. After rinsing the tissue with cold saline, the mucosa was scraped, weighed, and homogenized in $1.15 \% \mathrm{KCl}$. The homogenate was supplemented with the mixture of TBARS and boiled at $100{ }^{\circ} \mathrm{C}$ for $1 \mathrm{~h}$. The reactants were then supplemented with $5 \mathrm{ml}$ of the mixture of $n$-butanol and pyridine, shaken vigorously for $1 \mathrm{~min}$ and centrifuged for $10 \mathrm{~min}$ at $4000 \mathrm{rpm}$. Absorbance was measured at $532 \mathrm{~nm}$, and 1,1,1,3-Tetraethoxypropane was used as the standard. Data are expressed as a percentage of the control.

\section{Protein isolation}

The colonic samples obtained from mice were homogenized (1:3, w/v) in PBS supplemented with $0.1 \%$ sodium dodecyl sulfate (SDS), $0.1 \%$ sodium deoxycholate, $1 \%$ Triton $\mathrm{X}-100$ and protease inhibitors for iNOS and COX-2. For determine activities of NF- $\mathrm{B}$ (p50), nuclear extract were prepared from frozen colonic tissue by modification of the method of Deryckere and Gannon [21]. Briefly, the colonic tissue $(0.1 \mathrm{~g})$ was homogenized in $1 \mathrm{ml}$ buffer A [0.6\% NP-40, $150 \mathrm{mM} \mathrm{NaCl}$, $10 \mathrm{mM}$ HEPES (pH 7.9), $1 \mathrm{mM}$ EDTA, and $0.5 \mathrm{mM}$ PMSF] using a Dounce homogenizer. The homogenate was centrifuged at $200 \times \mathrm{g}$ for $30 \mathrm{~s}$ at $4{ }^{\circ} \mathrm{C}$. The supernatant was transferred to a clean tube, incubated on ice for $5 \mathrm{~min}$, and then centrifuged again at $5000 \times \mathrm{g}$ for $10 \mathrm{~min}$ at $4{ }^{\circ} \mathrm{C}$. The supernatant was discarded and the pellet was resuspended in $100 \mu \mathrm{l}$ buffer B, and then centrifuged at $2,700 \times \mathrm{g}$ for $3 \mathrm{~min}$ at $4{ }^{\circ} \mathrm{C}$. The supernatant was discarded and the pellet was re-suspended in $100 \mu 1$ buffer B [420 mM NaCl, $20 \mathrm{mM}$ HEPES (pH 7.9), $0.2 \mathrm{mM}$ EDTA, $0.5 \mathrm{mM}$ PMSF, $1.2 \mathrm{mM} \mathrm{MgCl}_{2}$, $0.5 \mathrm{mM}$ DTT, and $25 \%$ glycerol] containing a protease inhibitor cocktail (Boehringer, Mannheim, Germany), incubated on ice for $1 \mathrm{~h}$, and then centrifuged at $11,000 \times \mathrm{g}$ for $10 \mathrm{~min}$ at $4{ }^{\circ} \mathrm{C}$. The amount of protein in the supernatant was measured by the Lowry method [18] and stored at $-70{ }^{\circ} \mathrm{C}$ prior to use.

\section{Western blot analysis}

The protein extracts were analyzed on a $10 \%$ polyacrylamide mini-gel electrophoresis at $100 \mathrm{~V}$ for $2 \mathrm{~h}$ at room temperature using a Mini-PROTEIN II electrophoresis cell (Bio-Rad). After transfer onto nitrocellulose membranes (Millipore, Bedford, MA, USA), the membrane was incubated for $1 \mathrm{~h}$ at room temperature in TBS-T solution $(10 \mathrm{mM}$ Tris- $\mathrm{HCl}, \mathrm{pH} 7.6,150 \mathrm{mM} \mathrm{NaCl}$ and $0.1 \%$ Tween-20) containing $5 \%$ non-fat dry milk. The membranes were subsequently incubated for $2 \mathrm{~h}$ at room temperature with a 1:3,000 dilution of rabbit polyclonal antibodies [NF- $\kappa \mathrm{B}$ (p50), iNOS, COX-2, and $\alpha$-tubulin, Santa Cruz Biotechnology, CA, USA] in TBS-T solution. After three time washes with TBS-T, the membranes were incubated for $1 \mathrm{~h}$ at room temperature with alkaline 
phosphatase-conjugated goat anti-rabbit $\mathrm{IgG}$ $(1: 10,000$; Santa Cruz Biotechnology, CA, USA) in TBS-T. The protein bands were visualized by incubation with nitrobluetetrazolium (NBT) and 5bromo-4-chloro-3-indolylphosphate (BCIP) (Sigma Chemical Co.). The results obtained from western blot assay were calculated with the using of the Scion imaging software (Scion Image Beta 4.02, Maryland, USA) as the relative intensity to the control.

\section{Measurement of antioxidative enzyme activities}

The antioxidative enzyme activities in $\mathrm{A} / \mathrm{J}$ mice was measured according to the methods of Beauchamp and Fridovich [22] for SOD, Thomson et al. [23] for CAT, and Paglia and Valentine [24] for GPx. Colonic tissue was homogenized with $5 \mathrm{ml}$ of a $0.25 \mathrm{M}$ sucrose buffer ( $\mathrm{pH} 7.5$ ) containing $10 \mathrm{mM}$ EDTA. The homogenates were then centrifuged at $600 \times \mathrm{g}$ for $10 \mathrm{~min}$ at $4{ }^{\circ} \mathrm{C}$ to remove nuclear fractions, and the remaining separated supernatant was re-centrifuged at $10,000 \times \mathrm{g}$ for 20 min at $4{ }^{\circ} \mathrm{C}$ to collect the mitochondrial fraction (pellet) for a CAT assay. The supernatant was ultra-centrifuged at $100,000 \times \mathrm{g}$ for $1 \mathrm{~h}$ at $4{ }^{\circ} \mathrm{C}$ to isolate the cytosolic fraction for an SOD and GPx assays. The amount of protein was measured using the Lowry method [18] and the proteins were stored at $-70{ }^{\circ} \mathrm{C}$ for further experimental use. One unit of antioxidant enzymes are defined as the amount of enzyme required to reduce the NBT by $50 \%$ for SOD at $560 \mathrm{~nm}$, to reduce $1 \mu \mathrm{M}$ of $\mathrm{H}_{2} \mathrm{O}_{2} /$ min for CAT at $220 \mathrm{~nm}$, and to oxidize $1 \mu \mathrm{M}$ of $\mathrm{NADPH} / \mathrm{min}$ for GPx at $340 \mathrm{~nm}$, respectively, and the values were calculated as relative percentages to the control value.

\section{Statistical analysis}

All the data from in vivo $(n=6)$ experiments were expressed as means $\pm \mathrm{SD}$. A one-way analysis of variance (ANOVA) and the Duncan test were used for multiple comparisons (SPSS program, ver 11.0).

\section{Results}

\section{General observation}

Throughout the experiments, any mice were not died in each group. There was no significant difference of the water consumption and food intake in each group during all experimental periods. The mice treated with $3 \%$ DSS for 7 days were showed symptoms of acute colitis at an incidence of $100 \%$. The loose stool was first detected on the third day, and diarrhea sere observed on the fifth day of 3\% DSS treatment. On the sixth days, the rectal bleeding was also showed in $83 \%$ of the $3 \%$ DSS-treated mice. After 7 days treatment with 3\% DSS, the colon was shortened in all mice, except for control and GJE glycoprotein treatment alone group (Figure 1B, C). However, the administration of GJE glycoprotein ameliorated DSS-induced ulcerative symptoms in a dose-dependent manner, with suppression of diarrhea, rectal bleeding and loss of body weight as well as shortening of colonic length. For instance, when the mice were administered with GJE glycoprotein $(80 \mathrm{mg} / \mathrm{kg}$ BW) prior to $3 \%$ DSS treatment, the DAI value was significantly diminished by 2.4 on the seventh days, compared to the $3 \%$ DSS treatment alone (Figure 1A).

\section{Effect of GJE glycoprotein on MPO activity}

The colitis caused by $3 \%$ DSS was also characterized by increase in MPO activity, an indicator of the polymorphonuclear leukocyte accumulation in the colon (Figure 2). When the mice were treated with 3\% DSS in absence of GJE glycoprotein, the level of MPO activity was significantly increased by $65.5 \%$, compared to the $3 \%$ DSS treatment alone. However, the administration of GJE glycoprotein (40 and $80 \mathrm{mg} / \mathrm{kg} \mathrm{BW}$ ) prior to $3 \%$ DSS treatment resulted in the gradual decrease of MPO activity by 35 and $47 \%$, compared to the $3 \%$ DSS treatment alone, respectively.

\section{Effect of GJE glycoprotein on ROS production}

The inhibitory effect of GJE glycoprotein on ROS production caused by LPS in RAW 264.7 cells was shown in Figure 3. Here, it should be noted that scavenging effect of GJE glycoprotein on ROS is assessed in RAW 264.7 cells treated with LPS, because life span of ROS is millisecond. GJE glycoprotein treatment resulted in dose-dependent inhibition of LPS-stimulated ROS production in RAW 264.7 cells. For example, when the RAW 264.7 cells were treated with LPS $(200 \mathrm{ng} / \mathrm{ml})$, the 


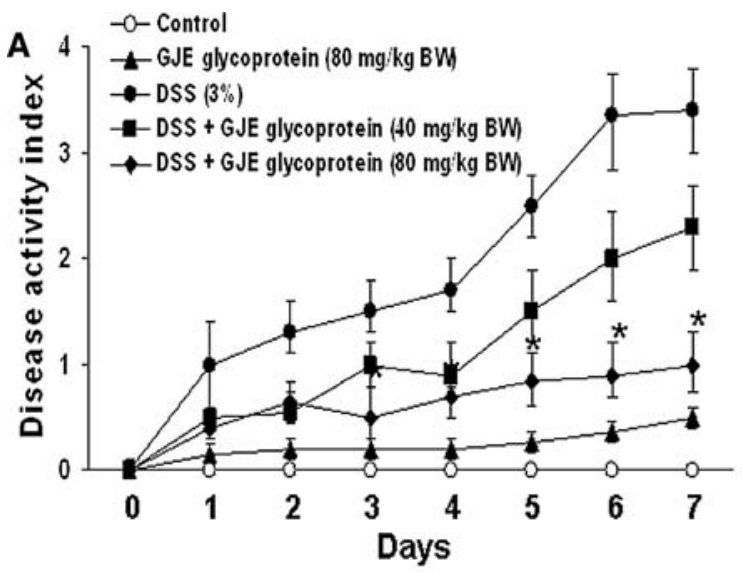

C Control
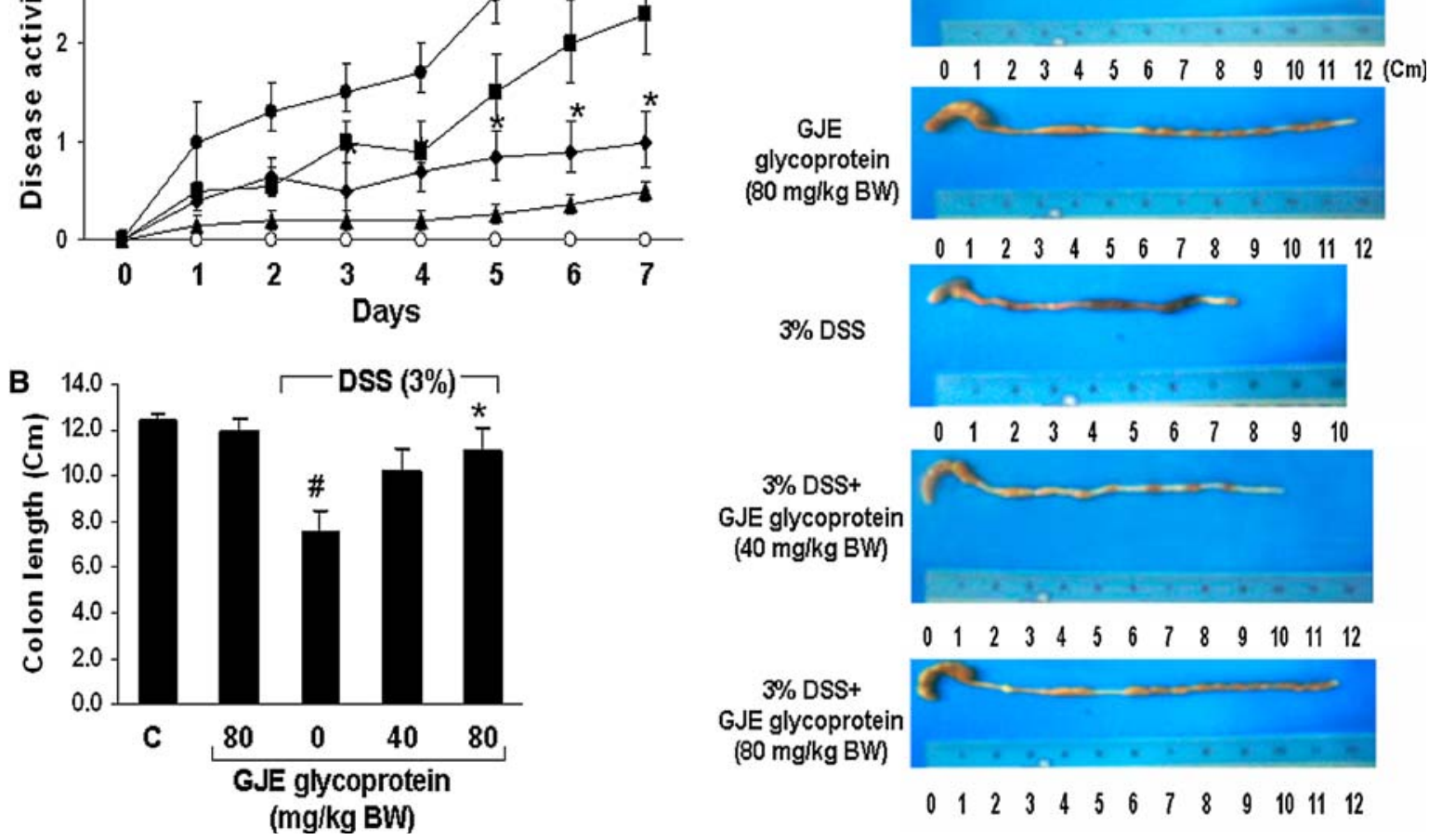

Figure 1. Effect of GJE glycoprotein on disease activity index and colonic length in DSS-induced mouse ulcerative colitis. Experimental colitis in mice was induced by a 3\% DSS dissolved in the drinking water for 7 days. GJE glycoprotein was administered orally at doses of 40 or $80 \mathrm{mg} / \mathrm{head} /$ body weight $(\mathrm{kg})$ once a day for 10 days prior to $3 \%$ DSS supplement. Changes in disease activity index (A), and colon length (B) at 3\% DSS treatment either in the presence or absence of GJE glycoprotein. Microscopic view of colon length at $3 \%$ DSS treatment either in the presence or absence of GJE glycoprotein (C). *represents significant difference between GJE glycoprotein treated with 3\% DSS and the 3\% DSS treatment group. $p<0.05$.

levels of ROS were gradually increased, compared to the control. However, the treatment GJE glycoprotein $(80 \mu \mathrm{g} / \mathrm{ml})$ in presence of LPS $(200 \mathrm{ng} / \mathrm{ml})$ were significantly diminished by 1.2 at incubation time of $4 \mathrm{~h}$, compared to the LPS $(200 \mathrm{ng} / \mathrm{ml})$ treatment alone.

\section{Effect of GJE glycoprotein on plasma nitric oxide (NO) production}

The effect of GJE glycoprotein on the levels of plasma NO in DSS-administered mice was evaluated and presented in Figure 4. When mice were treated with DSS in the absence of GJE glycoprotein, the level of plasma NO was markedly increased by $16.6 \mu \mathrm{M}$, compared to the control. However, the level of plasma NO gradually decreased after the addition of GJE glycoprotein (40 and $80 \mathrm{mg} / \mathrm{kg} \mathrm{BW}$ ) in the presence of DSS, although the levels of plasma NO in the presence of GJE glycoprotein did not change significantly without DSS.

\section{Inhibitory effect of GJE glycoprotein on lipid peroxidation}

The effect of GJE glycoprotein on lipid peroxidation in 3\% DSS-administered mice was represented in Figure 5. The result was showed the level of TBARS as a marker of colonic lipid peroxidation, and expressed as relative percentages. The treatment of $80 \mathrm{mg} / \mathrm{kg}$ GJE glycoprotein in the absence of 3\% DSS did not change in the level of TBARS. In the 3\% DSS-treated mice, the level of 


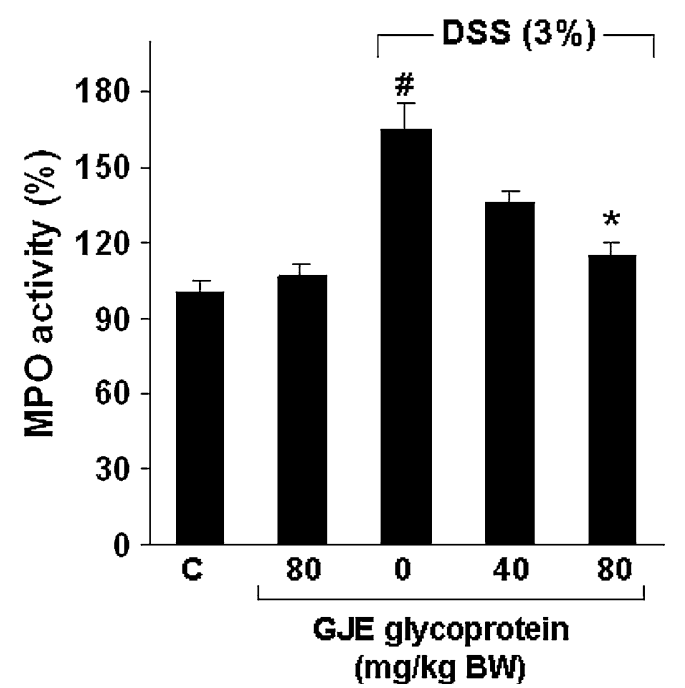

Figure 2. Effect of GJE glycoprotein on myeloperoxidase (MPO) activity in DSS-treated mouse colon tissue. Experimental colitis in mice was induced by a 3\% DSS dissolved in the drinking water for 7 days. GJE glycoprotein was administered orally at doses of 40 or $80 \mathrm{mg} / \mathrm{head} /$ body weight $(\mathrm{kg})$ once a day for 10 days prior to $3 \%$ DSS supplement. The level of tissue MPO was determined in accordance with a standard enzymatic procedure, as described in the "Materials and methods" section. Each bar represents the means \pm SD from triplicate experiments $(n=6)$. ${ }^{\text {\#represents a significant differ- }}$ ence with the control, $p<0.01$. *represents a significant difference between GJE glycoprotein treated with 3\% DSS and the $3 \%$ DSS treatment group, $p<0.05$. C: control.

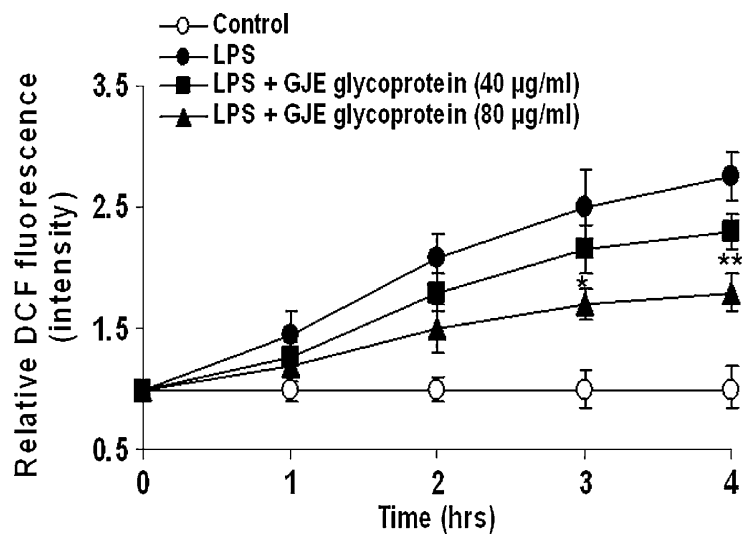

Figure 3. Effect of GJE glycoprotein on ROS production in LPS-stimulated RAW 264.7 cells. The relative intensity was calculated by monitoring dichlorodihydrofluorescein (DCF) fluorescence using fluoresencent microplate reader (Dual Scanning SPECTRAmax, Molecular Devices Corporation, Sunnyvale, CA, USA). Data represent the means \pm SD from triplicate experiments $(n=3)$. * and ** represent significant differences between GJE glycoprotein treatments in presence of LPS $(200 \mathrm{ng} / \mathrm{ml})$ and LPS $(200 \mathrm{ng} / \mathrm{ml})$ treatment alone, $p<0.05$ and $p<0.01$, respectively.

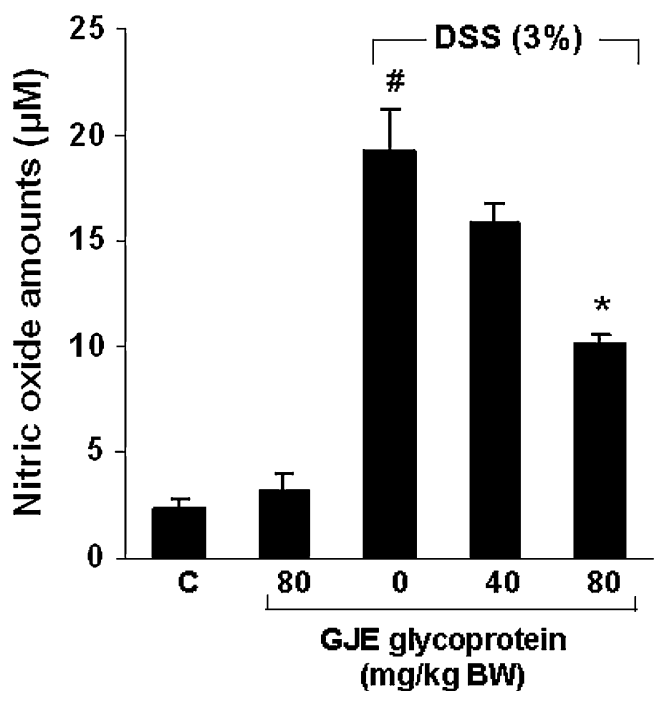

Figure 4. Effect of GJE glycoprotein on nitric oxide (NO) production in mouse plasma. NO production by treatment of GJE glycoprotein were measured and assessed indirectly by measuring the nitrite levels in mice serum, as described in "Materials and methods" section. Each bar represents the means \pm SD from triplicate experiments $(n=6)$. " represents a significant difference with the control, $p<0.01$. *represents a significant difference between GJE glycoprotein treated with $3 \%$ DSS and the $3 \%$ DSS treatment group, $p<0.05$. C: control.

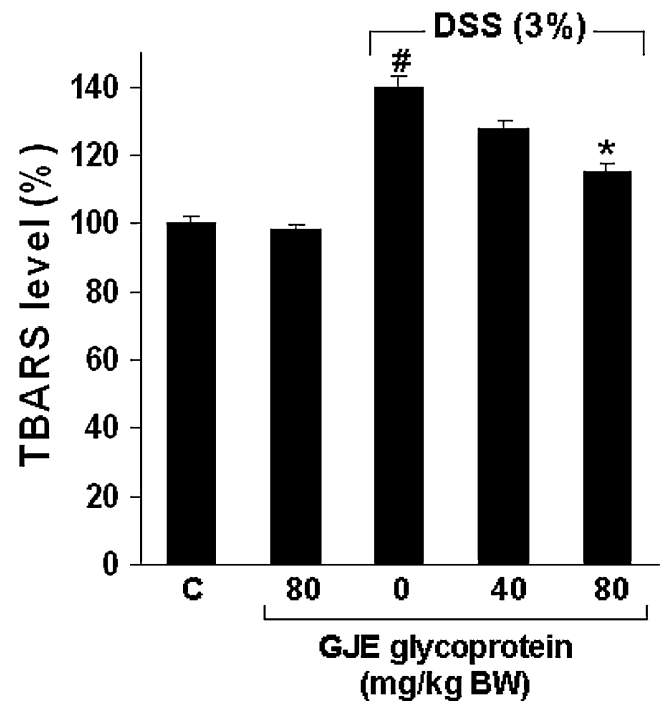

Figure 5. Inhibitory effect of GJE glycoprotein on lipid peroxidation in DSS-treated mouse colon tissue. Lipid peroxidation was estimated according to the presence of TBARS, as described in "Materials and methods" section. Each bar represents the means $\pm \mathrm{SD}$ from triplicate experiments $(n=6)$. ${ }^{\#}$ represents a significant difference with the control, $p<0.01$. *represents a significant difference between GJE glycoprotein treated with $3 \%$ DSS and the $3 \%$ DSS treatment group, $p<0.05$. C: control. 
TBARS was significantly increased by $38.9 \%$, compared to the control. However, the administration of GJE glycoprotein prior to $3 \%$ DSS supplement resulted in the gradual decrease of TBARS levels by 11.9 and $22.7 \%$, compared with the $3 \%$ DSS treatment group, respectively.

Effects of GJE glycoprotein on iNOS, COX-2 and $N F-\kappa B(p 50)$ activities

When the mice were treated with $3 \%$ DSS, the levels of inflammation related proteins (iNOS and COX-2) in inflamed tissue is significantly increased (Figure 6, lane 3). Upon pretreatment with the GJE glycoprotein (40 and $80 \mathrm{mg} / \mathrm{kg}$ ), however, the intensities of bands were obviously weakened in a dose-dependent manner (Figure 6, lanes 4 and 5). For instance, the values of relative band intensities of increased COX-2 and iNOS expression caused by DSS were diminished by 0.72 and 1.05 at
$80 \mathrm{mg} / \mathrm{kg}$ GJE glycoprotein, respectively, compared to the DSS treatment alone. Furthermore, the activity of transcription factor $(\mathrm{NF}-\kappa \mathrm{B}$ p 50) in inflamed tissue also gradually attenuated by addition of GJE glycoprotein. When the mice were treated with $3 \%$ DSS, the value of relative band intensity was increase by 2.1 . In contrast, the administration of GJE glycoprotein (40 and $80 \mathrm{mg} / \mathrm{kg} \mathrm{BW})$ prior to $3 \%$ DSS treatment resulted in the gradual decrease the relative activity of NF- $\kappa \mathrm{B}$ (p50) by 0.54 and 1.12 at 40 and $80 \mathrm{mg} / \mathrm{kg}$, compared to the $3 \%$ DSS treatment alone.

\section{Effects of GJE glycoprotein on antioxidative} enzymes activities

To investigate whether the antioxidative activities of GJE glycoprotein are mediated by an increase in antioxidative enzymes, the SOD, CAT, and GPx,

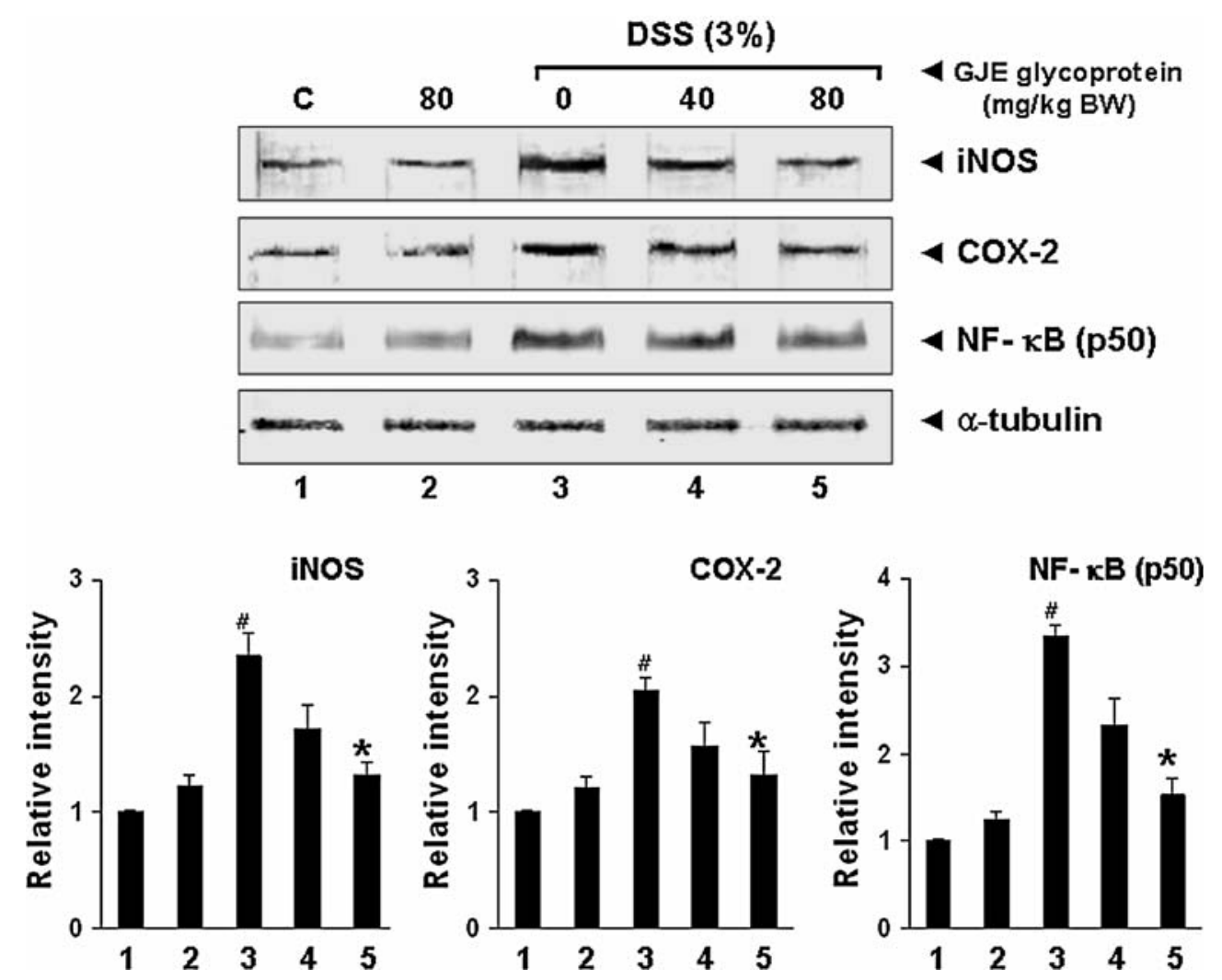

Figure 6. Effect of GJE glycoprotein on COX-2 and iNOS production, and NF- $\kappa \mathrm{B}$ p50 activity in DSS-treated mouse colon tissue. The protein extracts were obtained in inflamed colon tissue, as described in the "Materials and methods". $\alpha$-tubulin was used as an internal control. Activities of COX-2, iNOS, and NF- $\mathrm{\kappa B}(\mathrm{p} 50)$ proteins were performed by western blotting using an antiCOX-2, iNOS, and NF- $\kappa B$ (p50) polyclonal antibodies. The relative intensity was calculated using of the Scion Imaging Software (Scion Image Beta 4.02, Maryland, USA). ${ }^{\#}$ represents a significant difference with the control, $p<0.01$. * represents a significant difference between GJE glycoprotein treated with 3\% DSS and the 3\% DSS treatment group, $p<0.05$. C: control. 
activities in colonic extract from 3\% DSS-treated mice were examined following administration of GJE glycoprotein. As shown in Figure 7, when mice were treated with GJE glycoprotein alone, the activities of the SOD and GPx were significantly higher than the control group, although the activity of CAT did not change. For instance, the activities of SOD and GPx in the presence of the GJE glycoprotein were increased by 15.1 and $18.8 \%$, compared to the control. At treatment with 3\% DSS for 7 days, however, it was significantly diminished by $12.1,19.8$, and $35.5 \%$ for SOD, CAT, and GPx, compared to the control. On the other hand, when the mice were treated with $3 \%$ DSS after treatment with $80 \mathrm{mg} / \mathrm{kg}$ BW GJE glycoprotein, the activities of antioxidant enzymes significantly increased by $8.8,11.2$, and $36.4 \%$ for SOD, CAT, and GPx, compared to the $3 \%$ DSS treatment alone, respectively. The activity of GPx at treatments DSS alone and combination of GJE glycoprotein with DSS showed to be bigger than that of other two enzymes.

\section{Discussion}

In the present study, we demonstrated for the first time that GJE glycoprotein has an anti-inflammatory effect on the colon injury provoked by oral administration of DSS in mice. We initially examined whether GJE glycoprotein has an inhibitory effect on LPS-stimulated RAW 264.7 cells. Since activated macrophage can lead to overproduction of ROS in inflamed tissue, and recruitment of additional inflammatory cells including neutrophils and monocytes, the LPS was used as an activator of macrophages in this study. Our results were showed that GJE glycoprotein reduces the levels of ROS production in LPS-stimulated RAW 264.7 cells, pointing out its radical scavenging and anti-inflammatory properties in vitro.

DSS-induced colitis is a well established model that is similar to ulcerative colitis in human [2, 25]. Although the underlying mechanism of DSS is not fully understood, it is believed to be associated with the opening of tight junctions, thus increasing permeability [26]. These changes in epithelial structure allow the permeation of luminal antigens into the mucosa and the consequent inflammatory response [27]. The decrease of colitis induced by the GJE glycoprotein (40 and $80 \mathrm{mg} / \mathrm{kg} \mathrm{BW}$ ) was accompanied by a lower incidence of diarrhea and loss of weight of the mice, as provided the decreased DAI. The infiltration of leukocytes into the mucosa contributes significantly to the tissue necrosis and mucosal

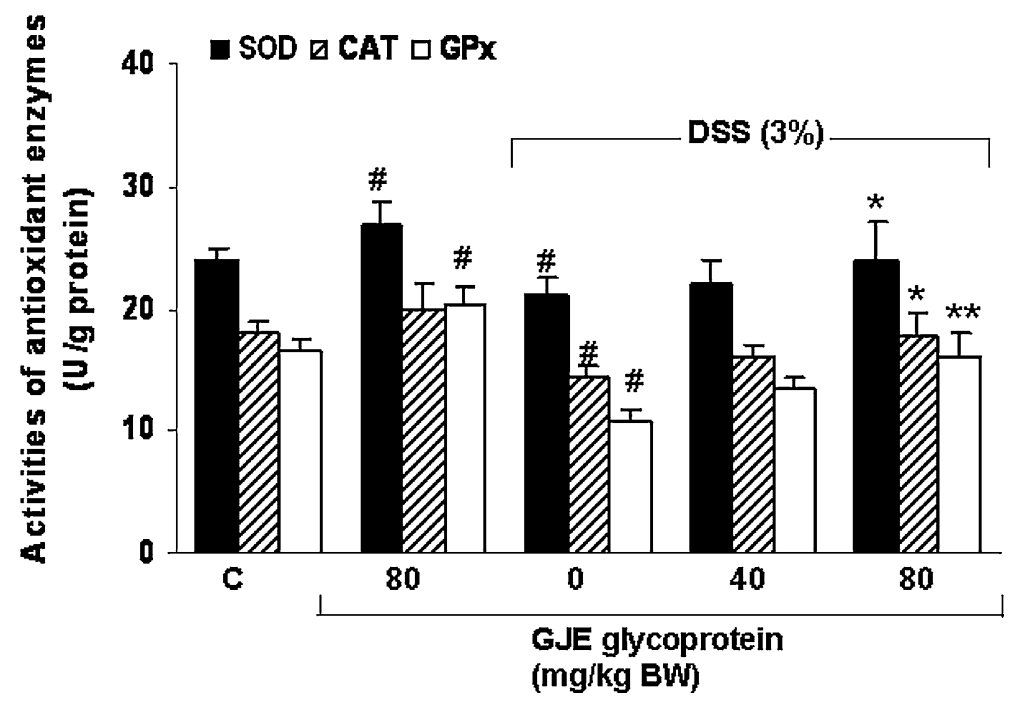

Figure 7. Effects of GJE glycoprotein on antioxidative enzymes activities in DSS-treated mouse colon tissue. Specific activities of antioxidative enzymes in the colons of mice were measured using SOD, CAT, and GPx assays, as described in "Materials and methods" section. The activities of SOD, CAT and GPx were represented as unit/mg protein in each supernatant and the values were calculated as a relative percentage to the control value. Each bar represents the means \pm SD from triplicate experiments $(n=6) .{ }^{\#}$ represents a significant difference with the control, $p<0.01 .{ }^{*}$ represents a significant difference between GJE glycoprotein treated with $3 \%$ DSS and the $3 \%$ DSS treatment group, $p<0.05$. C: control. 
dysfunction, as they represent a major source of ROS in the inflamed colonic mucosa [28]. MPO is an enzyme found predominantly in neutrophils, and a good marker of inflammation and tissue injury. Therefore, the decrease of MPO activity by agents can be explained the diminution of neutrophils accumulation into the inflamed tissue, thus inhibits the colitis. In addition, produced oxygen radicals and NO can interact and exert its cytotoxic effect by causing lipid peroxidation, resulting in the formation of malondialdehyde (MDA). The peroxynitrite $\left(\mathrm{ONOO}^{-}\right)$production can also lead to the production of inflammatory cytokines, enhanced recruitment and activation of leukocytes, accelerated apoptosis, and parenchymal cell necrosis [29]. In our experiments, the increased levels of MPO activity and TBARS were significantly inhibited by addition of GJE glycoprotein on inflamed tissues of $3 \%$ DSSinduced mice. It means that a decrease in lipid peroxidation leads to a reduction of colonic inflammation. From the obtained results, we speculate that GJE glycoprotein has anti-oxidative effects and counteractive effects against DSS, thus inhibit the lipid peroxidation in inflamed tissue of DSS-induced mice. The possible explanation may be due to enhancing antioxidant enzymes by the supplement of GJE glycoprotein and/or its antioxidant effect. Indeed, treatment with GJE glycoprotein resulted in an increase in activities of SOD and GPx, although it did not result in a significant change in the activity of CAT, compared to the control. However, their values in the DSS-treated mouse colon gradually increased in concentration after the treatment with GJE glycoprotein, compared to the DSS treatment alone. One of the possible mechanisms for lowering antioxidant enzyme activities is that the SOD, CAT, and GPx can be degraded or saturated to block the DSS-induced massive ROS production. SOD plays an important role in protecting cells from oxidative damage by converting superoxide radicals into hydrogen peroxide. Produced hydrogen peroxide is further metabolized by CAT and GPx, where CAT detoxifies hydrogen peroxide and GPx catalyses the destruction of hydrogen peroxide and lipid peroxide. Interestingly, GJE glycoprotein in this study stimulates to the antioxidant enzymes. A possible reason why SOD, CAT and GPx activities were augmented after GJE glycoprotein treatment in the presence of DSS is that GJE glycoprotein possesses not only the capacity to scavenge a small number of ROS in normal aerobic metabolisms, but it also has the capacity to block the DSS-induced massive ROS production, suggesting that the antioxidative potential of GJE glycoprotein seems to stimulate activities of antioxidant enzymes during DSS-induced colitis.

Furthermore, inhibition of iNOS production in inflamed tissue suggests that GJE glycoprotein is a latent inhibitor of iNOS production, thereby may function as relatively safe modulators of $\mathrm{NO}$ for various pathologic conditions. In addition to iNOS, production of COX-2 was also inhibited by addition of GJE glycoprotein in presence of DSS. The overproduced $\mathrm{PGE}_{2}$ via $\mathrm{COX}-2$ activation gives rise to pain, swelling, and stiffness [30, 31]. Since the production and activity of both iNOS and COX-2 are induced by same proinflammatory stimulus and are associated with inflammatory conditions, we think that inhibition of both iNOS and COX-2 would provide the most potent anti-inflammatory effect. Although the present investigation cannot establish the mechanism of interaction between NOS and COX activity, the possible mechanism is that inhibition of NO by GJE glycoprotein influence the COX-2 activity, thus may modulate the inflammation. Further, it is reported earlier that NO can stimulate COX activity via its reaction with heme component of the COX enzyme [31,32]. Accumulating evidence has suggested that the gene expression of iNOS and COX-2 can be also regulated by several transcription factors such as nuclear factor interleukin-6 (NF-IL6), FOS/JUN, CCAAT/enhancer-binding protein $(\mathrm{C} / \mathrm{EBP})$, and nuclear factor kappa $\mathrm{B}(\mathrm{NF}-\kappa \mathrm{B})[11,12]$. One of transcription factors, $\mathrm{NF}-\kappa \mathrm{B}$ has been implicated in many inflammatory diseases and has been shown to be activated by oxidative stress in the inflamed gastrointestinal tract [33]. The $N F-\kappa B$ family includes the proteins $\mathrm{p} 50$ and its precursor p105

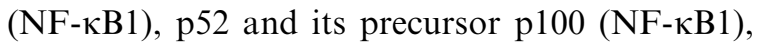
p65 (RelA), c-Rel, and Rel B. Generally, NF-кB can exist as either a heterodimeric or homodimeric complex, but it is classically composed predominantly of p50 and p65 subunits [10]. Recently, it reported that a heterodimeric or homodimeric complex of p50 and p65 appear to have proinflamatory activity in DSS-induced colon tissue,

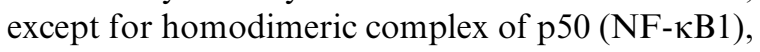


because p50 homodimer may block the activation of some inflammatory gene promoters [33-37]. These mean that either p50-p65 heterodimer or p65-p65 homodimer complex can exist in DSSinduced colon tissue. As shown in Figure 6, our result in present study showed that the activity of $\mathrm{NF}-\kappa \mathrm{B}(\mathrm{p} 50)$ in inflamed tissue markedly increased after treatment with DSS, indicating that DSS treatment may stimulate the formation of heterodimer complex of p50 and p65 in colon, although we did not detect the activity of p65 subunit. However the DSS-induced the activations of NF$\kappa \mathrm{B}(\mathrm{p} 50)$ was markedly inhibited by treatment with GJE glycoprotein in a dose-dependent manner, suggesting that GJE glycoprotein is a potential inhibitor of DSS-induced NF- $\mathrm{BB}$ (p50) activation in inflamed colon tissue. Additionally, it was welldefined that several binding sites for $\mathrm{NF}-\kappa \mathrm{B}$ are located in the enhancer- or basal promoter region of pro-inflammatory genes including COX-2 and iNOS $[11,12]$. Namely, iNOS and COX-2 closely relates to NF- $\kappa \mathrm{B}$ activation. These phenomenons also imply the involvement of serial signal mediators (NF- $\kappa \mathrm{B}, \mathrm{COX}-2$, and iNOS) in DSS-induced colitis. Also, these observations also support the above results that DSS-induced oxidative stress can activate NF- $\mathrm{kB}, \mathrm{COX}-2$, and iNOS, and that GJE glycoprotein blocks these activations of redox-sensitive serial signal mediators in inflamed colon tissue. Consequently, our findings suggest that GJE glycoprotein effectively scavenges ROS and protects colon from DSS-induced colitis in mouse.

In conclusion, the results showed that GJE glycoprotein has the ability to lower DAI, to inhibit MPO activity, to block lipid peroxidation, to reduce ROS production and NO levels, and to increase antioxidant enzymes activities. Also it showed the inhibitory effect of GJE glycoprotein on inflammation related signals [NF-KB (p50), iNOS, and COX-2] in inflamed tissue. From finding results, it suggests that GJE glycoprotein has therapeutic properties in ulcerative colitis by inhibiting the reactive oxygen and nitrogen species. To elucidate the precise mechanism of the inhibitory effect of GJE glycoprotein in the further studies must be evaluated cytokine levels (IL-1, IL-8, TNF- $\alpha$ ), NF-кB (p65), and the gene expression level with EMSA in the inflammatory process.

\section{Acknowledgements}

This study was financially supported by Chonnam National University in 2005.

\section{References}

1. Campbell S. and Ghosh S., Ulcerative colitis and colon cancer: strategies for cancer prevention. Dig. Dis. 20: 38 48, 2002.

2. Krawisz J.E., Sharon P. and Stenson W.F., Quantitative assay for acute intestinal inflammation based on myeloperoxidase activity. Assessment of inflammation in rat and hamster models. Gastroenterology 87: 1344-1350, 1984.

3. Grip O., Janciauskiene S. and Lindgren S., Macrophages in inflammatory bowel disease. Curr. Drug Targets Inflamm. Allergy 2: 115-160, 2003.

4. Yoshida N., Yoshikawa T., Yamaguchi T., Naito Y., Tanigawa T., Murase H. and Kondo M., A novel watersoluble vitamin E derivative protects against experimental colitis in rats. Antioxid. Redox Signal 1: 555-562, 1999.

5. Ohshima H. and Bartsch H., Chronic infections and inflammatory processes as cancer risk factors: possible role of nitric oxide in carcinogenesis. Mutat. Res. 305: 253-264, 1994.

6. Skrzydlewska E., Sulkowski S., Koda M., Zalewski B., Kanczuga-Koda L. and Sulkowska M., Lipid peroxidation and antioxidant status in colorectal cancer. World J. Gastroenterol. 11: 403-406, 2005.

7. Kruidenier L. and Verspaget H.W., Antioxidants and mucosa protectives: realistic therapeutic options in inflammatory bowel disease? Mediators Inflamm. 7: 157-162, 1998.

8. Galvez J., Application of natural products in experimental models of intestinal inflammation in rats. Methods Find. Exp. Clin. Pharmacol. 18: 7-10, 1996.

9. Nosal'ova V., Bobek P., Cerna S., Galbavy S. and Stvrtina S., Effects of pleuran (beta-glucan isolated from Pleurotus ostreatus) on experimental colitis in rats. Physiol. Res. 50: 575-581, 2001.

10. Chen F., Castranova V., Shi X. and Demers L.M., New insights into the role of nuclear factor- $\kappa \mathrm{B}$, a ubiquitous transcription factor in the initiation of diseases. Clin. Chem. 45: 7-17, 1999.

11. Xie Q.W., Kashiwabara Y. and Nathan C., Role of transcription factor NF- $\kappa \mathrm{B} / \mathrm{Rel}$ in induction of nitric oxide synthase. J. Biol. Chem. 269: 4705-4708, 1994.

12. Wadleigh D.J., Reddy S.T., Kopp E., Ghosh S. and Herschman H.R., Transcriptional activation of the cyclooxygenase-2 gene in endotoxin-treated RAW 264.7 macrophages. J. Biol. Chem. 275: 6259-6266, 2000.

13. Chang H.M. and But P.P.H., Pharmacology and Applications of Chinese Materia Medica, 2nd ed. World Scientific Publishing, Singapore, 1987, p. 1005.

14. Lee S.J., Oh P.S., Ko J.H., Lim K. and Lim K.T., Glycoprotein isolated from Gardenia jasminoides Ellis has a scavenging activity against oxygen radicals and inhibits the oxygen radical-induced protein kinase $\mathrm{C}$ alpha and nuclear factor-kappa B in NIH/3T3 cells. Environ. Toxicol. Pharmacol. 21: 8-21, 2006. 
15. American Society of Mammalogists Animal Care and Use Committee, Guidelines for the capture, handling, and care of mammals as approved by the American Society of Mammalogists. J. Mammal. 79: 1416-1431, 1998.

16. Kitajima S., Takuma S. and Morimoto M., Changes in colonic mucosal permeability in mouse colitis induced with dextran sulfate sodium. Exp. Anim. 48: 137-143, 1999.

17. Cooper H.S., Murthy S.N., Shah R.S. and Sedergran D.J., Clinicopathologic study of dextran sulfate sodium experimental murine colitis. Lab. Invest. 69: 238-249, 1993.

18. Lowry O.H., Rosebrough N.J., Farr A.L. and Randall R.J., Protein measurement with the Folin phenol reagent. J. Biol. Chem. 193: 265-275, 1951.

19. Green L.C., Wagner D.A., Glogowski J., Skipper P.L., Wishnok J.S. and Tannenbaum S.R., Analysis of nitrate, nitrite, and $[15 \mathrm{~N}]$ nitrate in biological fluids. Anal. Biochem. 126: 131-138, 1982

20. Ohkawa H., Ohishi N. and Yagi K., Assay for lipid peroxides in animal tissues by thiobarbituric acid reaction. Anal. Biochem. 95: 351-358, 1979.

21. Deryckere F. and Gannon F., A one-hour minipreparation technique for extraction of DNA-binding proteins from animal tissues. Biotechniques 16: 405, 1994.

22. Beauchamp C. and Fridovich I., Superoxide dismutase improved assays and an assay applicable to acrylamide gels. Anal. Biochem. 44: 276-287, 1971.

23. Thomson J.F., Nance S.L. and Tollaksen S.L., Spectrophotometric assay of catalase with perborate as substrate. Proc. Soc. Exp. Biol. Med. 157: 33-35, 1978.

24. Paglia D.E. and Valentine W.N., Studies on the quantitative and qualitative characterization of erythrocyte glutathine peroxidase. J. Lab. Clin. Med. 70: 158-169, 1967.

25. Okayasu I., Hatakeyama S., Yamada M., Ohkusa T., Inagaki Y. and Nakaya R., A novel method in the induction of reliable experimental acute and chronic ulcerative colitis in mice. Gastroenterology 98: 694-702, 1990.

26. Bjorck S., Jennische E., Dahlstrom A. and Ahlman H., Influence of topical rectal application of drugs on dextran sulfate-induced colitis in rats. Dig. Dis. Sci. 42: 824-832, 1997.

27. Suzuki Y., Deitch E.A., Mishima S., Duran W.N. and Xu D.Z., Endotoxin-induced mesenteric microvascular changes involve iNOS-derived nitric oxide: results from a study using iNOS knock out mice. Shock 13: 397-403, 2000 .

28. Guo X., Wang W.P., Ko J.K. and Cho C.H., Involvement of neutrophils and free radicals in the potentiating effects of passive cigarette smoking on inflammatory bowel disease in rats. Gastroenterology 117: 884-892, 1999.

29. Guzik T.J., Korbut R. and Adamek-Guzik T., Nitric oxide and superoxide in inflammation and immune regulation. J. Physiol. Pharmacol. 54: 469-487, 2003.

30. Morham S.G., Langenbach R., Loftin C.D., Tiano H.F., Vouloumanos N., Jennette J.C., Mahler J.F., Kluckman K.D., Ledford A., Lee C.A. and Smithies O., Prostaglandin synthase 2 gene disruption causes severe renal pathology in the mouse. Cell 83: 473-482, 1995.

31. Seibert K., Zhang Y., Leahy K., Hauser S., Masferrer J., Perkins W., Lee L. and Isakson P., Pharmacological and biochemical demonstration of the role of cyclooxygenase-2 in inflammation and pain. Proc. Natl. Acad. Sci. USA 91: 12013-12017, 1994.

32. Posadas I., Terencio M.C., Guillen I., Ferrandiz M.L., Coloma J., Paya M. and Alcaraz M.J., Co-regulation between cyclo-oxygenase- 2 and inducible nitric oxide synthase expression in the time-course of murine inflammation. Naunyn. Schmiedebergs Arch. Pharmacol. 361: 98-106, 2000.

33. Barnes P.J. and Karin M., Nuclear factor-kappaB: a pivotal transcription factor in chronic inflammatory diseases. N. Engl. J. Med. 336: 1066-1071, 1997.

34. Schreiber S., Nikolaus S. and Hampe J., Activation of nuclear factor kappa B inflammatory bowel disease. Gut 42: 477-484, 1998.

35. Kunsch C. and Rosen C.A., NF-kappa B subunit-specific regulation of the interleukin- 8 promoter. Mol. Cell. Biol. 13: 6137-6146, 1993.

36. Ledebur H.C. and Parks T.P., Transcriptional regulation of the intercellular adhesion molecule-1 gene by inflammatory cytokines in human endothelial cells. Essential roles of a variant NF-kappa B site and p65 homodimers. J. Biol. Chem. 270: 933-943, 1995.

37. Ziegler-Heitbrock H.W., Sternsdorf T., Liese J., Belohradsky B., Weber C., Wedel A., Schreck R., Bauerle P. and Strobel M., Pyrrolidine dithiocarbamate inhibits NF-kappa $\mathrm{B}$ mobilization and TNF production in human monocytes. J. Immunol. 151: 6986-6993, 1993. 